\title{
BIOCHEMICAL MARKERS OF MYOCARDIAL INJURY
}

\author{
P.K. Nigam \\ Department of Cardiology, King George's Medical University, Lucknow
}

\begin{abstract}
The serum markers of myocardial injury are used to help in establishing the diagnosis of myocardial infarction. The older markers like aspartate amino-transferase, creatine kinase, lactate dehydrogenase etc. lost their utility due to lack of specificity and limited sensitivities. Among the currently available markers cardiac troponins are the most widely used due to their improved sensitivity, specificity, efficiency and low turn around time. Studies have shown that cardiac troponins should replace CKMB as the diagnostic 'gold standard' for the diagnosis of myocardial injury. The combination of myoglobin with cardiac troponins has further improved the accuracy in the diagnosis of acute coronary syndromes and thereby reducing the hospital stay and patients' money. Among the other new markers of early detection of myocardial damage, heart fatty acid binding protein, glycogen phosphorylase BB and myoglobin / carbonic anhydrase III ratio seem to be the most promising. But the search for the most ideal marker of myocardial injury is still on.
\end{abstract}

\section{KEY WORDS}

Cardiac markers, Myocardial infarction.

\section{INTRODUCTION}

Myocardial ischaemia results from the reduction of coronary flow to such an extent that supply of oxygen to the myocardium does not meet the oxygen demand of myocardial tissue. When this ischaemia is prolonged and irreversible then myocardial cell death and necrosis occurs which is defined as myocardial infarction (MI). The diagnosis of $\mathrm{MI}$ is based on clinical symptoms, electrocardiographic (ECG) changes and characteristic pattern of changes in some serum enzymes such as creatine kinase (CK), creatine kinase isoenzyme MB (CKMB), lactate dehydrogenase isoenzyme $1\left(\mathrm{LD}_{1}\right)$ and cardiac specific proteins like troponins $(1,2)$. Since the clinical symptoms are not very reliable, ECG is the most widely used method of the diagnosis of myocardial infarction. But many times ECG shows inconclusive pattern (3). In such a situation the importance of serum biochemical markers of myocardial injury arises to confirm the diagnosis of myocardial injury.

\section{Address for Correspondence :}

Dr. P.K. Nigam

Dept. of Cardiology

King George's Medical University,

Lucknow - 226003

\section{CRITERIA FOR A TRUE BIOCHEMICAL MARKER OF MYOCARDIAL INJURY}

1. It should be myocardial tissue specific and its concentration in the myocardium should be high but should be absent in non-myocardial tissues.

2. It should be detectable in blood soon after the myocardial injury i.e. the sensitivity should be high.

3. It should remain elevated in blood for several days of the onset of damage so that it can be detected in patients coming to the hospital quite late after myocardial infarction.

4. It could be assayed by simple and quick method i.e. the turn-around time (TAT) should be low because the first few hours of myocardial infarction are crucial for medical intervention.

\section{FACTORS RESPONSIBLE FOR RELEASE OF MARKERS FROM THE MYOCARDIAL TISSUE AND THEIR APPEARANCE IN THE BLOOD}

Myocardial ischaemia and ischaemia / reperfusion activates several protein kinase pathways. Protein kinase activation potentially regulates the onset of myocardial cell injury and the reduction of this injury by ischaemic and pharmacologic preconditioning. The primary protein kinase pathways that are potentially activated by myocardial ischaemia / reperfusion 
are the MAP kinases, ERK 1/2, JNK 1/2, p38 MAP kalpha/beta; the cell survival kinase, Akt and the sodium-hydrogen exchanger (NHE) kinase, p90RSK (4).

Oxygen deprivation due to prolonged ischaemia leads to a cascade in the metabolism in the myocardial tissues beginning from anaerobic glycolysis, inhibition of ATP-dependent transport process in cell membrane, electrolyte shift, cellular edema and to finally loss of cell membrane integrity. Due to increased glycolysis lactate concentration decreases the intracellular $\mathrm{pH}$ resulting in release and activation of lysosomal proteolytic enzymes and thereby disintegrating intracellular structures and structurally bound proteins. The release and appearance of these ischaemia affected biomolecules in the blood stream is an outcome of these metabolic changes. Thus the appearance of these markers in the blood stream and their measurable life in the blood following ischaemia depends on :

1. Their intracellular location or compartmentation - The molecules present in cytosol are released first when myocardial damage occurs whereas the structurally bound molecules are released later.

2. Their molecular weight - The larger molecules diffuse at a slower rate than the smaller molecules.

3. Their rate of elimination from the blood - The smaller molecules are eliminated rapidly as compared to larger molecules.

4. Blood flow in the necrotic region - The difference in the circulation of blood in the infarcted area leads to differences in the release of cytosolic proteins from the necrotic region while the release of structurally bound proteins are independent of the blood flow in the infarcted region.

\section{CRITERIA USED TO ASSESS THE DIAGNOSTIC VALUE OF THE MARKER OF MYOCARDIAL INFARCTION}

1. Diagnostic sensitivity - is the probability of a positive test result in patients and indicates how surely patients with MI would produce a positive test result.

number of infarction patients with (correct) positive test results

Diagnostic sensitivity $=$

number of all infarction patients tested.

2. Diagnostic specificity - is the probability of a negative test result in a healthy subject and it indicates the frequency of a negative result in patients who do not have an infarction.

number of non-infarction patients with negative test results

Diagnostic specificity = number of all non-infarction patients tested.

3. Predictive value - is the probability that the disease in question is actually present if the test result is positive.

number of infarction patients with positive test results

Predictive value $=$ (positive)

number of infarction patients with positive and non infarcted patients with false positive results

number of non-infarction patients with negative test results

Predictive value $($ negative $)=$

number of all (correct and false) negative results

4. Diagnostic Efficiency - is the over all proportion of correct (both positive and negative) test results for all the subjects tested.

\section{BIOCHEMICAL MARKERS OF MYOCARDIAL INJURY IN SERUM / PLASMA}

1. Aspartate aminotransferase.

2. Lactate dehydrogenase and its isoenzyme $L_{1}$

3. Creatine kinase and its isoenzyme MB

4. Myoglobin

5. Cardiac Troponins.

6. Myoglobin/Carbonic anhydrase III ratio

7. Glycogen phosphorylase isoenzyme BB

8. Heart fatty acid binding protein.

\section{ASPARTATE AMINOTRANSFERASE (AST/GOT)}

The levels of serum AST activity begin to rise 3-8 hours after the onset of the myocardial injury with peak levels on an average at 24 hours and finally it returns to normal levels in 36 days (5). It was considered as a very good marker of cardiac injury as it was found to be normal in pulmonary embolism, 
acute abdominal conditions and other heart conditions such as angina and pericarditis $(6,7)$. But later on, its use become limited due to its elevation in trauma to skeletal muscles and liver diseases $(8,9)$.

\section{LACTATE DEHYDROGENASE (LD) AND ITS ISOENZYME LD}

An increase in serum LD activity is found following myocardial infarction beginning within $6-12$ hours and reaching a maximum at about 48 hours and it remains elevated for 4-14 days before coming down to normal levels. The prolonged elevation makes it a good marker for those patients admitted to the hospital after several days of MI. However, its use is discouraged due to its non-specificity as its increased levels are found in progressive muscular dystrophy, myoglobinuria, leukaemia, pernicious anaemia, megaloblastic and hemolytic anaemia, renal disease and in generalized carcinoma (5).

LD has five isoenzymes $\left(L D_{1}, L D_{2}, L D_{3}, L D_{4}\right.$ and $\left.L D_{5}\right)$. The cardiac muscles are rich in $L D_{1}$ and $L D_{2}\left(L_{1}>L D_{2}\right)$ while in liver $L D_{3}, L D_{4}$ and $L D_{5}$ being plentiful. The differential distribution of LD isoenzymes makes its use in differential diagnosis as a marked increase in the proportion of $L D_{1}$ in the serum in $\mathrm{MI}$ and $\mathrm{LD}_{5}$ in liver disease has been found. $\mathrm{LD}_{1}$ manifests the greatest catalytic activity in reducing $\alpha$-oxobutyrate to $\alpha$-hydroxybutyrate, hence it is termed as $\alpha$-hydroxybutyrate dehydrogenase (10) and it was considered to be more sensitive marker of MI than total LD and it remained elevated even longer than total LD. Moreover, $\alpha$-hydroxybutyrate dehydrogenase stayed normal or showed small increase in hepatitis.

\section{CREATINE KINASE (CK) AND ITS ISOENZYME MB (CKMB)}

Serum CK activity increases following MI beginning within 6 hours and peaking on an average at 24 hours and returning to normal within 2-3 days. The area under the peak and the slope of the initial rise are proportional to the size of the infarction (5). However, its presence in large amounts in skeletal muscle and increased levels found in muscular dystrophy (11), hypothyroidism (12), hypothermia (13), alcoholism (14), cerebrovascular accidents (15) and a variety of myopathies (16) make it unsuitable as a marker of myocardial injury.

CK has three isoenzymes namely CKBB, CKMB and CKMM each consisting of two subunits named according to main tissue of occurrence : B (brain) and $\mathrm{M}$ (skeletal muscles). Myocardium contains 40\% CKMB and 60\% CKMM along with traces of mitochondrial CK (macro CK type II) where as skeletal muscles contain about 97\% CKMM, 2-3\% CKMB and traces of CKBB and mitochondrial macro type II. Being highest in proportion in myocardium CKMB has been used as the biochemical marker in patients with suspected acute myocardial infarction (AMI).

Serum CK-MB kinetics gives useful information regarding the extent and timing of myocardial injury. It begins to increase between 3-5 hours after the onset of infarction and peaking at 16-20 hours. It has been considered as the 'Gold Standard' for confirmation of MI (17). However, the techniques used (electrophoresis and immunoinhibition) to quantitate CKMB catalytic activity were not sensitive enough for early use, being relatively non-specific and long turn-around time restricted its use primarily for confirming $\mathrm{Ml}$ at 24 hours post injury (18, 19). Recently, the measurement of mass concentration of $\mathrm{CKMB}$ has increased its sensitivity and specificity enabling to measure small changes during the early hours following MI. The turn-around time is also low. The CKMB mass assay has a diagnostic sensitivity of $50 \%$ at 3 hours. and $80 \%$ at 6 hours. It has been found that CKMB mass slope calculated from serial blood samples collected 0-12 hours after the onset is a rapid and accurate diagnostic approach to categorize the patients with suspected AMI $(20,21)$. Despite all these advantages of CKMB mass assay it has two main limitations : (1) it is not perfectly specific to cardiac injury with increases occurring also during massive musculoskeletal injury and (2) the early release pattern limits its use for the late $\mathrm{MI}$ diagnosis. But it has a definite place for the diagnosis of reinfarction (22) and has prognostic value in patients with unstable angina (23). Its potential as an aid in non-invasive detection of coronary recanalization following thrombolytic therapy (24) and also as a sensitive marker in detecting myocardial necrosis following percutaneous coronary intervention (25) has also been shown. The ratio of the CK-MB / total CK has also been proposed for the diagnosis of the origin of raised CK-MB by some authors $(26,27)$ but it has been discouraged by others due to certain limitations $(28,29)$.

CK-MB isoforms (subtypes) are also considered as sensitive markers for early diagnosis of $\mathrm{MI}(30,31)$. There is only one $\mathrm{CKMB}$ isoform within tissue but after release into the circulation CKMB is chemically modified resulting in two bands on traditional high voltage electrophoresis : one tissue subtype $M B_{2}$ and the other the modified subtype $M_{1}$. The ratio of $\mathrm{MB}_{1} / \mathrm{MB}_{2}$ provides the basis for a positive MB subtype result (32-34). However, CKMB isoforms offer no advantage over CKMB mass as early marker of MI (35) and CKMB mass measurement is more practical to perform in the laboratory 
and easily automated than the measurement of CKMB isoforms with available methods.

\section{MYOGLOBIN}

Myoglobin, a $18 \mathrm{KD}$ cytosolic protein, appears in blood earlier after myocardial injury than any other marker available so far. The detectable levels of myoglobin in the blood are found as early as 2 to 3 hours after the onset. Its peak value is obtained at $6-12$ hours after the onset of the symptoms and then it normalizes over the next 24 hours. However, it is not cardiac specific as its release from the skeletal muscles cannot be distinguished from that released due to cardiac injury (36) and it is found to be elevated in severe renal insufficiency and in patients being on alcohol binges immediately prior to coming to emergency room (37). Several studies have compared the diagnostic utility of serum myoglobin with other markers like CKMB, CKMB mass, CKMB isoforms and cardiac Troponins but the results have been controversial (35,38-42). The high negative predictive value of serum myoglobin for excluding early infarction has encouraged its use along with more specific markers such as CKMB and cardiac troponin and this two marker approach has improved the diagnosis of MI (43).

\section{TROPONINS}

Troponin is a protein complex located on the thin filament of striated muscles consisting of the three subunits namely Troponin $\mathrm{T}(\mathrm{TnT})$, Troponin I ( $\mathrm{Tnl}$ ) and Troponin C ( $\mathrm{TnC}$ ) each having different structure and function. Of the three troponins, $\mathrm{TnT}$ and $\mathrm{Tnl}$ are being used as the biochemical markers for the diagnosis of myocardial injury. The troponins found in cardiac tissue (cTn) have a different amino acid sequence than that present in troponin of skeletal muscles. This makes cTnT and cTnl more specific for the diagnosis of myocardial injury. These cardiac troponins (cTns) appear in the blood as early as 3-4 hours of the acute episode and remain elevated for 4-14 days. The pattern of release of troponin may be monophasic or biphasic. This release kinetics is related to the distribution of these proteins within the myocardial cell. About $94-97 \%$ of these troponins is bound to myofibril and only $3 \%$ of cTnl and $6 \%$ of cTnT is free in the cytoplasm (44, 45). When the myocardial damage occurs the cytosolic troponins reach the blood stream quickly resulting in a rapid peak of serum troponin observed during the first few hours. This is followed by the release of structurally bound troponin resulting in a second peak lasting for several days. However, in patients with non-reperfused AMI (permanent occlusion), only a single continuous peak is observed (44).

cTnT and cTnl are now regarded as the most specific biochemical markers of myocardial injury (46). Studies have shown that cardiac troponins should replace CKMB as the diagnositic 'gold standard' for the diagnosis of myocardial injury. The reasons being :

1. Troponins are highly cardiospecific especially the Tnl (100\%).

2. The prolonged elevation (4-14 days) make it a good marker for patients admitted to the hospital after several days of $\mathrm{Ml}$.

3. cTns have greater sensitivity for minor degrees of myocardial injury $(47,48)$ due to the cardiospecificity and their very low concentration in serum of normal individuals. ${ }^{1}$

4. These are excellent prognostic indicator in patients with unstable angina $(49,50)$ and is a very useful parameter for stratifying risk in acute coronary syndrome* (ACS) patients (51-54) and their predictive value is superior to that of CKMB alone (55).

5. A single measurement of serum cTnT at the time corresponding to the slow continuous release after AMI ( 72 hours after onset) can be used as a convenient and cost effective non-invasive estimate of infarct size whereas CKMB requires repetitive sampling (43).

6. The early serial measurements of cTnl are a more accurate predictor of early coronary artery reperfusion after thrombolytic therapy as compared to CKMB and myoglobin (56) and it also identifies a subgroup of patients with unstable coronary syndrome in whom prolonged antithrombotic treatment with low-molecular weight heparin can improve the prognosis.

7. According to U.S. National Academy of Clinical Biochemistry (NACB) and Joint European Society of Cardiology and American College of Cardiology (ESC/ ACC) guidelines cTns are the most specific and sensitive biochemical markers. However, different cut off values have been used to differentiate between ACS and $\mathrm{AMI}(57,2)$.

\section{cTnT Versus cTnl}

Both cTnT and cTnl are almost equally good markers and it is difficulty to say which is better because both have some positive and negative points. cTnl is $100 \%$ cardiospecific and as apposed to cTnT it is not elevated in chronic renal disease, trauma and skeletal muscle disease (58). The overall

\footnotetext{
* Acute coronary syndromes covers the clinical spectrum of acute myocardial ischaemia, including unstable angina, acute myocardial infarction without ST-segment elevation and ST-segment elevation MI.
} 
diagnostic specificity and efficiency of cTnl is better than cTnT (59) and it (cTnl) is proved to be the most sensitive marker in detecting myocardial necrosis following percutaneous intervention (25). However, the third generation cTnT assays don't allow the skeletal TnT interference. Both cTns undergo posttranslational modifications such as phosphorylation, oxidation, reduction, proteolysis and form complex with other troponins. cTnl is more prone to these modifications and these modification may prevent some antibodies used in the assay system from binding to the molecules and thereby diminishing the signal. There are some discrepancies in the standardization of cTnl assays. The same sample tested with assays from different manufacturers may give several fold difference in results where as cTnT assay in manufactured by only one manufacturer (43). The life-time of cTnT in blood (514 days) is some what more than that of cTnl (4-10 days).

Although cardiac troponins are extremely specific for myocardial necrosis, they do not discriminate between ischaemic and non-ischaemic etiologies of myocardial injury. Combining troponin with other cardiac biomarkers may offer complimentary information on the underlying pathobiology and prognosis in an individual patient (60).

The recommended time course for collection of blood samples for cTn is at hospital admission, 6 and 12 hours later but when it is used along with an early marker like myoglobin (two-marker strategy) then at hospital admission, 4,8 and 12 hours later is used (43).

\section{MYOGLOBIN / CARBONIC ANHYDRASE III RATIO}

Carbonic anhydrase III (CA III) is present in skeletal muscles and is released into circulation following injury. But since it is not found in cardiac muscles it is used in combination with myoglobin as a marker of myocardial damage (61). The measurement of myoglobin / carbonic anhydrase III ratio improves the specificity of myoglobin as an early marker of MI $(62,63)$. The ratio was found significantly higher in patients with $\mathrm{MI}$ whereas myoglobin and CA III were released in a fixed ratio following exercise and showed no significant difference in the ratio for trauma patients (63). This ratio was also used in evaluating the success of reperfusion after MI (64). However, its use is limited due to lack of availability of commercial assay of CA III and it has no use in AMI with a delayed presentation.

\section{GLYCOGEN PHOSPHORYLASE BB}

Glycogen phosphorylase (GP) is a key enzyme of glycogenolysis and GPBB is its isoenzyme. Its release depends on the degradation of glycogen. With the onset of tissue hypoxia when glycogen is broken down, GPBB is converted from a structurally bound into a cytoplasmic form and thus the efflux of GPBB into the extracellular fluid follows ischaemia induced structural changes $(65,66)$. GPBB has been found to be a sensitive marker for the diagnosis of MI within 4 hours of chest pain but it also increases early in unstable angina and reversible ST-T alterations (67). It is also a sensitive marker for detection of perioperative myocardial injury in patients undergoing coronary artery bypass grafting (68). Infact, it is considered as the most promising marker among the recently proposed new markers for early diagnosis of AMI (69). However, it is cleared from the circulation within 24-72 hrs after $\mathrm{Ml}$, therefore it can not be used as a late marker of myocardial injury.

\section{HEART-TYPE FATTY ACID BINDING PROTEIN (H-FABP)}

It is a low molecular weight ( $15 \mathrm{KD}$ ) cytoplasmic protein present in myocardium and is released into the circulation following myocardial injury. Its plasma kinetics closely resembles those of myoglobin but it is more cardiospecific than myoglobin. It was found to be elevated within 3 hours after AMI and return to normal levels within 12-24 hours. Hence it is considered as a sensitive and specific marker of early detection of myocardial injury as compared to CKMB and / or $\alpha \mathrm{HBDH}$ and myoglobin (70-72). Infact, it has been shown to be the earliest marker for confirmation and exclusion of $\operatorname{AMI}(73,74)$. It also has a potential to be used as a prognostic indicator of myocardial damage as well as clinical outcome in paediatric cardiac surgery (75).

Several other but less extensively studied markers are cardiac myosin light chains $(76,77)$, S100aO (78) and annexin V (79).

\section{CONCLUSION}

It is clear from the foregoing review that none of the markers available so far meet all the criteria required for an ideal biochemical marker of myocardial injury. However, among the currently available markers cTns appear to be the most promising as far as their sensitivity, specificity, turn around time and cost is concerned. The improved sensitivity and specificity of cTns has almost eliminated the place of LD and $\mathrm{CK}$ and even CKMB in the diagnosis of cardiac injury. Between cTnT and cTnl, the latter seems to be better considering its cardiospecificity and efficiency. However, the discrepancies in its standardization limit it from being the best and much is needed to be done to harmonize the test results. For early 
detection of myocardial injury serum myoglobin is used as a sensitive marker but it lacks cardiospecificity. However, its combination with a more specific marker like cTns has improved the accuracy in the diagnosis of acute coronary syndrome and thereby reducing the hospital stay and patients money. Both ESC/ACC and NACB have proposed the use of myoglobin or CKMB isoforms for early diagnosis of $\mathrm{MI}$ in addition to highly specific cardiac makers such as cTnT or cTnl. Among the other new markers of early detection of myocardial damage, HFABP, GPBB and myoglobin/CA III ratio seem to be the most promising. But the search for the most ideal marker is still on.

\section{REFERENCES}

1. Nomenclature and criteria for diagnosis of Ischaemic Heart Disease : Report of the Joint International Society and Federation of Cardiology / World Health Organization Task Force on standardization of clinical nomenclature. Circulation 1979;59: 607-08.

2. Alpert JS, Thygeson K, Antman E, et al. Myocardial infarction redefined - a consensus document of the Joint European Society of Cardiology / American College of Cardiology Committee for redefinition of myocardial infarction. J Am Coll Cardiol 2000; 36: 959-69.

3. Mc Queen MJ, Holdir D, El-Maraglin NR. Assessment of the accuracy of serial electrocardiograms in the diagnosis of myocardial infarction. Am Heart J 1983;105:258-61.

4. Armstrong SC. Protein kinase activation and myocardial ischaemia / reperfusion injury. Cardiovasc Res 2004;61:42736.

5. Varley H, Gowenlock AH, Bell M. Enzymes, In : Practical Clinical Biochemistry, Vol. I, $5^{\text {th }}$ edn. William Heinemann Medical Books Ltd. London 1984; p685-770.

6. Baron DN, Bell JL, Oakley C. Serum transaminase in coronary thrombosis and other conditions. J Clin Path 1956;9: 389-90.

7. Agress CM. Evaluation of the transaminase test. Am J Cardiol 1979; 3:74-93.

8. Kachmar JR. Enzymes, In : Fundamentals of Clinical Chemistry, NW. Tietz, Editor Sounders, Philadelphia 1976;p 674.

9. Sacks HJ, Lanchantin GF. An elevation of serum transaminases in jaundice states. Am J Clin Path. 1960;33:97-108.

10. Elliot BA, Wilkinson JH, Serum " $\alpha$-hydroxybutyric dehydrogenase" in myocardial infarction and in liver disease. Lancet 1961;1:698-99.

11. Ebashi S, Toyokura $\mathrm{Y}$, Momoi H, Sugita H. High creatine phosphokinase activity of sera of progressive muscular dystrophy. J Biochem (Japan) 1959;46: 103-05.
12. Doran GR, Wilkinson JH. The origin of the elevated activities of creatine kinase and other enzymes in the sera of patients with myxedema Clin Chim Acta 1975;62: 203-07.

13. Zsigmond EK, Starkweather WH, Duboff GS, Flynn KA. Elevated Serum Creatine Phosphokinase activity in a family with malignant hyperpyrexia. Anesth Analg 1972;51: 827.

14. LaFair JS, Myerson RM. Alcoholic myopathy. Arch Intern Med 1968; 122: 417-19.

15. Dubo H, Park DC, Pennigton R, JT Kalbag RM, Walton JN. Serum creatine kinase in cases of stroke, head injury and meningitis. Lancet 1967;2: 743-48.

16. Vassella F, Richterich R, Rossi E. The diagnostic value of serum creatine kinase in neuromuscular and muscular disease. Paediatrics 1965;35: 322-30.

17. Lee TH, Goldman L. Serum enzymes assay in the diagnosis of acute myocardial infarction. Recommendation based on a quantitative analysis. Ann Intern Med 1986; 105: 221-33.

18. Seckinger DL, Vazquez DA, Rosenthal PK, Mendizabal RC. Cardiac isoenzyme methodology and the diagnosis of acute myocardial infarction. Am J Clin Pathol 1983; 80: 164-69.

19. Roberts R. Enzymatic diagnosis of acute myocardial infarction. Chest 1988;93: 3S-6S.

20. Collison PO, Rosalki SB, Kuwana T et al. Early diagnosis of acute myocardial infarction by CK-MB mass measurements. Ann Clin Biochem 1992;29:43-47.

21. Lott JA, Heinz JW, Reger KA. Time changes of creatine kinase and creatine kinase MB isoenzyme versus discrimination values in the diagnosis of acute myocardial infarction : what is the optimal method for displaying the data? Eur J Clin Chem Biochem 1995; 33: 491-96.

22. Panteghini M. Diagnostic application of CK-MB mas determination. Clin Chim Acta 1998;272:23-31.

23. Ravkilde J, Hansen AB, Horder M, Jorgensen PJ, Thygesen $K$. Risk stratification in suspected acute myocardial infarction based on a sensitive immunoassay for creatine kinase isoenzyme MB. Cardiology 1992;80: 143-51.

24. Grande P, Granborg J, Clemmensen P, Sevilla DC, Wagner NB, Wagner GS. Indices of reperfusion in patients with acute myocardial infarction using characteristics of the CK-MB time activity curve. Am Heart J 1991; 122:400-08.

25. Nageh T, Sherwood RA, Harris BM, Byrne JA, Thomas MR. Cardiac troponin $\mathrm{T}$ and $\mathrm{I}$ and creatine kinase - MB as markers of myocardial injury and predictors of outcome following percutaneous coronary intervention. Int $\mathrm{J}$ Cardiol 2003;92: 285-93.

26. El Allaf M, Chapelle JP, El Allaf E et al. Differentiating muscle damage from myocardial injury by means of the serum creatine kinase $(\mathrm{CK})$ isoenzyme $\mathrm{MB}$ mass measurement / total CK activity ratio. Clin Chem 1986;32:291-95. 
27. Thrompson WG, Mahr RG, Yohannan WS, Pincus MR. Use of creatine kinase MB isoenzyme for diagnosing myocardial infarction when total creatine kinase activity is high. Clin Chem 1988; 34: 2208-10.

28. Keffer JH. Myocardial markers of injury-evolution and insights. Am J Clin Pathol 1996; 105:305-20.

29. Arenas J, Diaz V, Liras G. et al Activities of creatine kinase and its isoenzymes in serum in verious skeletal muscle disorders. Clin Chem 1988; 34: 2460-62.

30. Puleo PR, Guadagno PA, Roberts R et al. Early diagnosis of acute myocardial infarction based on assay for subforms of creatine kinase - MB. Circulation 1990;82: 759-64.

31. Puleo PR, Meyer D, Wathen C et al. Use of a rapid assay of subforms of creatine kinase MB to diagnose or rule out acute myocardial infarction. N Engl J Med 1994; 331: 561-66.

32. Panteghini M. Serum isoforms of creatine kinase isoenzymes. Clin Biochem 1988;21:211-18.

33. Wu ABW. Creatine kinase isoforms in ischaemic heart disease. Clin Chem 1989; 35:7-13.

34. Prager NP, Suzuki T, Jaffe AS, Sobel BE, Abendschein DR. The nature and time course of generation of the isoforms of MB creatine kinase in vivo. J Am Coll Cardiol 1992; 20: 41419.

35. Pentilla K, Koukkunen $\mathrm{H}$, Halinen M, Rantanen T, Pyorala $\mathrm{K}$, Punnone PI. Myoglobin, creatine kinase $\mathrm{MB}$ isoforms and creatine kinase MB mass in early diagnosis of myocardial infarction in patients with acute chest pain. Clin Biochem 2002; 35: 647-53.

36. Christenson RH, Azzazy HM. Biochemical markers of the acute coronary syndromes. Clin Chem 1998; 44: 1855-1864.

37. Gilkeson G, Stone MJ, Waterman M, Ting R, GomezSanchez CE, Hull A, Willerson JT. Detection of myoglobin by radioimmunoassay in human sera : Its usefulness and limitations as an emergency room screening test for acute myocardial infarction. Am Heart J 1978; 95:70-75.

38. deWinter, Koster R, Sturk A, Sanders G. Value of myoglobin, troponin $\mathrm{T}$ and $\mathrm{CKMB} \mathrm{m}$ in ruling out an acute myocardial infarction in the emergency room. Circulation 1995;92: 3401-07.

39. Hetland O, Dickstein K. Cardiac markers in the early $h$ of acute myocardial infarction : clinical performance of creatine kinase, creatine kinase MB isoenzyme (activity and mass concentration), creatine kinase MM and MB isoform ratios, myoglobin and cardiac troponin T. Scand J Clin Lab Invest 1996; 56:701-13.

40. Jernberg T, Lindahl B, James S, Ranquist G, Wallentin L. Comparison between strategies using creatine kinase $-\mathrm{MB}$ (mass), myoglobin and troponin $\mathrm{T}$ in the early detection or exclusion of acute myocardial infarction in patients with chest pain and a non-diagnostic electrocardiogramm. Am J Cardiol 2000; 86: 1367-71.
41. Mair J, Morandell D, Genser N, Lechleitner P, Dienstl F, Puschendorf B. Equivalent early sensitivities of myoglobin, creatine kinase MB-mass, creatine kinase isoform ratios and cardiac tropinim I and $\mathrm{T}$ for acute myocardical infarction. Clin Chem 1995; 41:1266-72.

42. Zimmerman J, Fromm R, Meyer D. Diagnostic marker cooperative study for the diagnosis of myocardial infarction. Circulation 1999;99:1671-77.

43. Pantighini M. Biochemical markers in acute coronary syndromes. LabMedica International 2003;20(6): 6-7.

44. Katus HA, Remppis A, Scheffold T, Dienderich KW, Kubler W. Intracellular compartmentation of cardiac troponin $\mathrm{T}$ and its release kinetics in patients with reperfused and nonreperfused myocardial infarction. Am J Cardial 1991;67: 1360-67.

45. Adams JE, Schechtman KB, Landt $Y$ et at. Comparable detection of AMI by CK-MB isoenzyme and cardiac tropnin I. Clin Chem 1994; 40: 1291-95.

46. Tymchak WJ, Armstrong PW. Spectrum of ischaemic heart disease and the role of biochemical markers. Clin Lab Med 1997; 17: 701-25.

47. Rottbauer W, Greten T, Muller-Bard off M et al. Troponin T:A diagnostic marker for myocardial infarction and minor cell damage. Eur Heart J 1996; 17: (Suppl. F), 3-8.

48. Hamm CW. Cardiac-specific troponins in acute coronary syndromes in Braunwald, E (ed.) Heart Disease: A text-book of cardiovascular Medicine. $5^{\text {th }}$ ed 1997 Update vol.3. p 110.

49. Ravikilde J, Horder M, Gerhardt W, Ljungdahl J, Petterson $\mathrm{T}$, Tryding $\mathrm{N}$ et al. Diagnostic performance and prognostie value of serum Troponin $\mathrm{T}$ in suspected acute myocardial infarction. Send J Clin Lab Invest 1993; 53: 677-85.

50. Wu AHB, Feng YJ, Controls JH. Prognostic value of cardiac troponin I in chest pain patients. Clin Chem 1996;42:65152.

51. Galvani M, Ottari F, Ferrini D, Ladenson, JH, Destro A, Baccos $D$ et at. Prognostic influence of elevated values of cardiac troponin I in patients with unstable angina. Circulation 1997; 95: 2053-59.

52. Ohman EM, Armstrong PW, Christenson RH, Granger CB, Katus HA, Hamm CW et al. Cardiac troponin T levels for risk stratification in acute ischaemia. N Engl J Med 1996; 335: 133-41.

53. Olatidoye AG, Wu AH, Feng Y, Waters D. Prognostic role of Troponin $\mathrm{T}$ versus Troponin I in unstable Agnina Pectoris for cardiac events with meta-analysis comparing Published studies. Am J Cardiol 1998;81:1405-10.

54. Heidenreich PA, Allogiamento T, Melsop K, McDonald KM, Alan SGo, Heatky MA. The prognostic valve of troponin in patients with non-ST elevation acute coronary syndromes: a meta analysis. J Am Coll Cardiol 2001;38: 478-85. 
55. Rao SV, Ohman EM, Granger CB et al. Prognostic value of isolated troponin elevations across the spectrum of chest pain syndromes. Am J Cardiol 2003;91:936-40.

56. Apple FS, Henry TD, Berger CR, Landt YA. Early monitoring of serum cardiac Troponin I for assessment of coronary reperfusion following thrombolytic therapy. Am J Clin Path 1996;105: 6-10.

57. Wu AH, Apple FS, Gibler WB, Jesse RL, Warshaw MM, Waldes R Jr. National Academy of Clinical Biochemistry standards of Laboratory Practice: recommendations for the use of cardiac markers in coronary artery disease. Clin Chem 1999;45: 1104-21.

58. Bodor GS, Porterfield D, Voss E. et al. Cardiac troponin T composition in normal and regenerating human skeletal muscle (Abstract) Clin Chem 1995; 41: s148.

59. Ikeda J, Zenimoto M, Kita M, Mori M. Usefulness of cardiac troponin I in patients with acute myocardial infarction. Rinsho Byori 2002;50: 982-86.

60. Sciries BM, Morrow DA. Troponins in acute coronary syndromes. Prog Cardiovasc Dis 2004; 47:177-88.

61. Vaananen HK, Syrjala H, Rahkila P et al. Serum carbonic anhydrase III and myoglobin concentration in acute myocardial infarction. Clin Chem 1990; 36: 635-38.

62. Brogan GX Jr, Vuori J, Friedman S, Mc Cuskey CF, Thode HC Jr, Vaananen HK, Colling DS, Bock JL. Improved specificity of myoglobin plus carbonic anhydrase assary versus that of creatine kinase-MB for early diagnosis of acute myocardial infarction. Am Emerg Med 1996; 28: 245-46.

63. Beuerle JR, Azzazy HM, Styba G, Duh SH, Christenson RH. Characteristics of myoglobin, Carbonic anhydrase III and the myoglobin/ arbonic anhydrase III ratio in trauma, exercise and myocardial infarction patients. Clin Chim Acta 2000; 294 : 115-28.

64. Vuotikka P, Uusimaa P, Niemela M, Vaananen K, Vuori J, Peuhkurinen, K. Serum myoglobin/ Carbonic anhydrase III ration as a marker of reperfusion after myocardial infarction. Int J Cardiol 2003; 91: 137-44.

65. Krause EG, Rabitzsch G, Noll F, Mair J, Puschendorf B. Ghycogen phophorylase ischaemic injury and infarction. Mol Cell Biochem 1996;160-161: 289-95.

66. Mair J. Glycogen phophorylase isoenzyme BB to diagnose ischaemic myocardial damage. Clin Chem Acta 1998; 272: 79-86.

67. Mair J, Puschendorf B, Smidt J, Lechleitner P, Diestl F, Noll $\mathrm{F}$ et al. Early release of glycogen phosphorylase in patients with unstable angina and transient ST-T alteration. Br Heart J 1994; 72: 125-27.

68. Mair P, Mair J, Krause EG Balogh D, Puschendorf B, Rabitzsch G. Ghycogen phosphorylase isoenzyme BB mass release after coronary artery bypass grafting. Eur $\mathrm{J}$ Clin Chem Biochem 1994;32: 543-47.
69. Wu AH. Analytical and clinical evaluation of new diagnostic tests for myocardial damage. Clin Chem Acta 1998;272: 1121.

70. Kleine AH, Glatz JF, Van Nieuwenhoven FA, Vander Vusse GJ. Release of heart fatty acid-binding protein into plasma after acute myocardial infaction in man. Mol Cell Biochem 1992; 116: 155-62.

71. Ishii J, Wang JH, Naruse H, Taga S, Kinoshita M, Kurokawa $\mathrm{H}$, Iwase M, Kondo T, Nomura M, Nagamura Y, Watanabe Y, Hishida H, Tanaka T, Kawamura K. Serum concentrations of myoglobin Vs human heart-type cytoplasmic fatty acidbinding protein in early detection of acute myocardial infarction. Clin Chem 1997;43: 1372-78.

72. Okamoto F, Sohmiya K, Ohkaru Y, Kawamura K, Asayma K, Kimura $\mathrm{H}$, Nishimura S, Ishii $\mathrm{H}$, Sunahara $\mathrm{N}$, Tanaka $\mathrm{T}$. Human heart- type cytoplasmic fatty acid binding protein $(\mathrm{H}$ FABP) for the diagnosis of acute myocardial infarction. Clinical evaluation of $\mathrm{H}-\mathrm{FABP}$ in Comparison with myoglobin and creatine Kinase isoenzyme MB. Clin Chem Lab Med 2000; 38: 231-38.

73. Chan CP, Sanderson JE, Glatz JF, Chang WS, Hempel A, Renneberg R. A superior early myocardial infarction marker Human heart-type fatty acid binding protein. Z Kardiol 2004;93: 388-97.

74. Seino Y, Tomita Y, Takano T, Ohbayashi K. Office cardiologists cooperative study on whole blood rapid panel tests in patients with suspicious acute myocardial infarction: Comparison between heart-type fatty acid binding protein and Troponin T tests. Circ J 2004;68:144-48.

75. Hasegawa T, Yoshimura N, Oka S, Ootaki Y, Toyoda Y, Yamaguchi M. Evaluation of heart fatty acid-binding protein as rapid indicator of assessment of myocardial damage in pediatric cardiac surgery. Thorac Cardiovasc Surg 2004;127: 1697-02.

76. Isobe M, Nagai R, Ueda S et al. Quantitative relationship between left ventricular function and serum cardiac myosin light chain I level after coronary reperfusion in patients with acute myocardial infarction. Circulation 1987;76: 1251-61.

77. Panteghini M. Cardiac myosin light chains. Lab Med 1992; 23: 318-322.

78. Usui A, Kato K, Sara H, Minaguchi K, Abe T, Murase M, Tanaka M, Takeuchi E. S-100 a O protein in serum during acute myocardial infarction. Clin Chem 1990;36: 639-41.

79. Kaneko N, Matsuda R, Hosoda S, Kajita T, Ohta Y. Measurement of plasma annexin $\mathrm{V}$ by ELISA in early detection of acute myocardial infarction. Chin Chim Acta 1996;251: 65-80. 